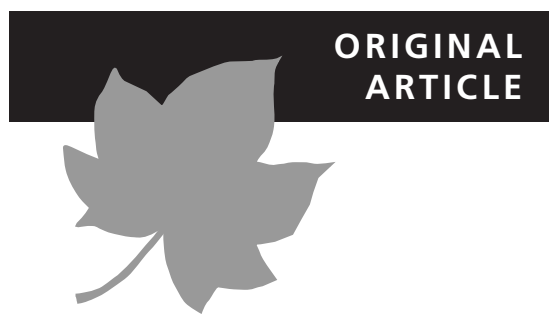

\title{
Time, area and isolation: factors driving the diversification of Azorean arthropods
}

\author{
Paulo A. V. Borges ${ }^{1 \star}$ and Joaquín Hortal ${ }^{1,2} \uparrow$
}

${ }^{1}$ Departamento de Ciências Agrárias - CITAA (Azorean Biodiversity Group), Universidade dos Açores, Terra-Chã, Angra do Heroísmo, Terceira, Açores, Portugal and ${ }^{2}$ NERC Centre for Population Biology, Imperial College London, Silwood Park Campus, Ascot, Berkshire, UK
${ }^{\star}$ Correspondence: Paulo A. V. Borges, Departamento de Ciências Agrárias - CITAA (Azorean Biodiversity Group), Universidade dos Açores, Terra-Chã, 9700-851 Angra do

Heroísmo, Terceira, Açores, Portugal. E-mail: pborges@uac.pt

$\dagger$ †oth authors contributed equally to this paper.

\section{ABSTRACT}

Aim R. J. Whittaker et al. recently proposed a 'general dynamic model of oceanic island biogeography' (GDM), providing a general explanation of island biodiversity patterns by relating fundamental biogeographical processes speciation, immigration, extinction - to area (A) and time ( $\mathrm{T}$; maximum island geological age). We adapt their model, which predicts a positive relationship with area combined with a humped relationship to time (designated the $\mathrm{ATT}^{2}$ model), to study the factors promoting diversification on the Azores for several arthropod groups.

Location The Azorean archipelago (North Atlantic; $37-40^{\circ} \mathrm{N}, 25-31^{\circ} \mathrm{W}$ ).

Methods We use the number of single-island endemics (SIEs) as a measure of diversification, to evaluate four different predictions for the variation in SIEs between different islands, derived from the GDM theory and our knowledge of the fauna and history of the Azores. We calculated the number of SIEs for seven out of the nine Azorean islands and six groups of species (all arthropods, beetles, cavernicolous and non-cavernicolous species, and taxa with high and low dispersal abilities). Several variables accounting for island characteristics (area, geological age, habitat diversity and isolation) and generalized linear models were used to evaluate the reliability of each prediction.

Results A linear and positive relationship between SIEs and an AT (area + time) model was the most parsimonious explanation for overall arthropod diversification. However, cavernicolous species showed the opposite pattern (more SIEs inhabiting the youngest islands). Also, isolation was an important predictor of diversification for all groups except for the species with high dispersal ability; while the former were negatively related to the distance from the main source of colonizing lineages (Santa Maria island in most cases), the latter were related to area. Dispersal ability was also a key factor affecting the diversification of most groups of species.

Main conclusions In general, the diversification of Azorean arthropods is affected by age, area and isolation. However, different groups are affected by these factors in different ways, showing radically different patterns. Although the ATT ${ }^{2}$ model fails to predict the diversification pattern of several groups, it provides a framework for integrating these deviations into a general theory. Further improvements of the GDM theory need to take into account the particular traits of each group and the role of isolation in shaping island diversity.

\section{Keywords}

Arthropods, Azores, beetles, cavernicolous species, dispersal, general dynamic model, island evolution, island geological age, single-island endemics, speciation. 


\section{INTRODUCTION}

The origin and maintenance of the diversity of species and lineages on isolated islands has been related to many factors, including island area, distance to the nearest source of propagules (usually the nearest mainland), habitat diversity (or its surrogate, maximum altitude) and geological age of the island (see reviews in Rosenzweig, 1995; Whittaker \& Fernández-Palacios, 2007). In their original formulation of the 'theory of island biogeography' (mainly based on area and isolation) MacArthur \& Wilson $(1963,1967)$ proposed that the number of species on an island tends to an equilibrium state resulting from the balance between immigration and extinction rates. They also recognized that within an isolated oceanic archipelago, species accumulate as a consequence of immigration and within-island speciation events [that is, long-distance dispersal (see Nathan, 2005) and diversification processes (see Emerson, 2002), respectively]. Thus, on isolated oceanic islands, in situ speciation is considered to be the most important diversitygenerating process, at least for taxa with low dispersal abilities (but see Coyne \& Price, 2000). In fact, young islands are expected to experience a 'dynamic interactive equilibrium', while on older islands there might be an upward adjustment to an 'evolutionary species equilibrium' (sensu Wilson, 1969) (note that here younger and older islands are relative terms that vary depending on the biological group studied; see also Williamson, 1988). Following the 'evolutionary species equilibrium model' of Wilson (1969) (see also Wilson \& Taylor, 1967), extinction rates decrease in the native fauna by means of evolution and, with a negligible effect from the immigration curve, there is an increase in species. Thus, according to the simple proposition of MacArthur and Wilson's model, current species diversity on islands is the outcome of three different processes: immigration, which determines the lineages present on each island; diversification, which results in the evolutionary divergence within some of these lineages; and extinction, which removes species and lineages through time.

The simplicity of MacArthur and Wilson's model has resulted in its long-term prevalence as one of the cores of current ecological knowledge, but also in a limited capacity to explain the diversity of patterns shown by island biotas in the large number of archipelagos scattered world-wide (Heaney, 2000). First, the importance of immigration (i.e. colonization) from mainland and from other islands within the archipelago varies widely between different archipelagos, depending on their geographical location and the (spatial and temporal) sparseness of their islands (see Thornton, 2007; Whittaker \& Fernández-Palacios, 2007). Second, there is a plethora of different diversification processes occurring within each archipelago, resulting in both the anagenetic evolution of new forms of some of the lineages arriving at each island (Stuessy et al., 2006) and in the cladogenetic divergence produced by the radiation of these lineages within the island (Losos, 1996; Schluter, 2000; Emerson, 2002; Gillespie, 2002; Gillespie \& Roderick, 2002). Additionally, the specific rates of extinction, colonization and diversification on each island, as well as the direction of these processes (i.e. the trend to the prevalence of particular adaptations or clades in a given moment of time) vary through time and between different groups of species. Islands in general, and oceanic islands of volcanic origin in particular, are dynamic entities that pass through different stages from the time of their formation (i.e. 'island ontogeny', sensu Stuessy, 2007), to their ultimate disappearance due to erosion and subsidence. Therefore, the geological evolution of volcanic islands produces important variations in the diversification rates through time (Stuessy, 2007; Whittaker et al., 2007, 2008). Volcanic eruptions can result in repeated phases of major habitat destruction in the archipelago, causing the extinction of local communities. Conversely, volcanic activity can also promote speciation as lava flows provide newly formed habitats where adaptive processes can occur, and can also act as barriers separating populations facilitating within-island vicariance processes.

The models for the evolution of island biotas and the geological dynamics of volcanic islands through time have recently been combined by Whittaker et al. $(2007,2008)$ to formulate the 'general dynamic model of oceanic island biogeography' (GDM). This model aims to provide a unitary (and general) framework to explain biodiversity patterns on non-continental islands by describing and quantifying the relationship of the above-mentioned fundamental biogeographical processes (immigration, speciation and extinction) with the geological evolution of islands through time. The GDM pays special attention to the effect of the drastic variations in the geomorphological structure of an island through time on the rates of diversification, extinction and (to some extent) immigration, based on the opportunities for speciation provided by these variations. Using the number of single-island endemics (SIEs) as a raw measure of diversification, and area and time (maximum island geological age) as descriptors of the stage of geological evolution of the island, Whittaker et al. (2008) showed empirically that a model based on area and a hump-shaped relationship with time called $\mathrm{ATT}^{2}$ [expected to be of the form $\log ($ Area $)+$ Time - Time $^{2}$ ] provides a better explanation of within-island speciation than the standard species-area model (SAR) for a range of different taxa in a number of oceanic archipelagos of volcanic origin. Based on their results for the Canary Islands, the Galapagos, Hawaii, the Marquesas and the Azores, they argue that if there is a sufficient array of island ages, the $\mathrm{ATT}^{2}$ model can describe the distribution of SIEs across a volcanic oceanic archipelago. If the array of island ages is smaller, such as in young archipelagos (e.g. the Azores or the Galapagos), the GDM model predicts that only the ascending portion of the humpshaped relationship with age will be found.

Here, we use the framework provided by the GDM and the associated $\mathrm{ATT}^{2}$ model (Whittaker et al., 2008) to study the patterns of diversification of arthropods on the Azorean islands. First we evaluate the generality of Whittaker et al.'s model and then we identify some of its limitations. The Azores is an isolated oceanic archipelago composed of recent islands of heterogeneous volcanism, which arose in a complex and 
widely scattered fashion around the mid-Atlantic oceanic ridge. The particular configuration of the Azores results in a relatively high isolation of some islands within the archipelago. This, together with the complex origin and different types of volcanism of the Azorean islands and their relatively small range of geological ages, results in lower correlations between biogeographically relevant island characteristics (age, area and isolation) than in other oceanic archipelagos such as the Canary Islands or Hawaii. Based on the predictions of the GDM model and our knowledge of the characteristics of the Azorean biota and the geological dynamics of volcanic islands, we make four testable predictions about the diversification of arthropods on the Azores, as follows.

\section{Prediction 1: In general, the diversification of Azorean arthropods will be better described by an AT (area + time) model}

The Azores are composed of relatively young islands (all of them are $<10 \mathrm{Myr}$ old, and all but one are $<5 \mathrm{Myr}$ old); most of them are still in the first stages of their geological evolution according to Whittaker et al.'s (2008) description. Therefore the relationship between SIEs and time for Azorean arthropod taxa will be positive and linear, as we expect it to include only the initial, ascending phase of the hump-shaped curve predicted by the GDM model (see also Whittaker et al., 2008).

\section{Prediction 2: The number of SIEs in cavernicolous groups will be higher in the youngest islands than expected according to the GDM model based on island area, and will rather be related to the number and length of caves}

One of the potential limitations of the GDM model arises from its aim of generality, which necessarily implies that opportunities for speciation and extinction rates are relatively similar for all groups through the evolution of the island. Although this could be true for many taxa, we expect some exceptions to appear, depending on the particular use of space and therefore of the perception of habitat heterogeneity of each particular group, as well as on their generation time and raw diversification rate. We hypothesize that cave-adapted species (also called troglobites - cavernicolous species hereafter) are one of these groups. For this group, the number and length of caves will be a better measure of the available space than island area. In the earlier stages of development of an island, volcanic activity creates a diverse underground environment in the form of lava tubes, volcanic pits and pit-caves. Once the level of volcanic activity subsides, these caves progressively reduce their extension and disappear as the island ages, due to erosive processes. Therefore, the opportunity for speciation for cavernicolous groups will be higher in the early stages of development of the island, and also extinction rates will increase earlier in the island life cycle than in the majority of the groups (see Prediction 3 below). However, these species can persist in suboptimal conditions in the MSS ('milieu souterrain superficiel' or 'mesovoid shallow substratum', sensu Culver, 2001). As a consequence, the number of cavernicolous SIEs will be higher on younger islands, showing a negative relationship with geological age, or no relationship at all, if parts of recent origin within old islands continue to provide a sufficient number of caves (such as São Miguel in the Azores). Furthermore, their number will be more related to the number of cave habitats than to general measures of island area. In essence, we hypothesize that cavernicolous fauna will follow an accelerated progression through the stages of GDM, and that for this group the number of cave habitats will be equivalent to area in the original GDM formulation.

Prediction 3: The number of SIEs will be related to the isolation of each island, showing (1) a negative relationship with the distance from Santa Maria, the oldest island, and (2) a positive relationship with the distance to nearby islands

The relative isolation of each island is commonly thought to affect diversification rates in two different and opposing ways (see Heaney, 2000, 2007; Heaney et al., 2005). (1) On the one hand, isolation from the possible sources of propagules (mainland or older islands) has a negative effect on the number of SIEs, since the number of lineages that arrive at the island and can diversify there decays with the distance from the sources (e.g. Canary Islands). Speciation rates peak relatively early in island age, when there are plenty of opportunities in the form of 'empty niche space' (e.g. Gillespie, 2004; Levin, 2004; Stuessy, 2007; see also Whittaker \& Fernández-Palacios, 2007; Whittaker et al., 2008). Therefore, it can be hypothesized that islands arising near to older islands would receive greater numbers of lineages during these initial stages, resulting in a comparatively larger number of both archipelago endemics and SIEs when the island biota reaches an equilibrium state than islands arising further away. The Azores provide an excellent field test for this hypothesis, since colonization and evolutionary processes started on the oldest island (Santa Maria, $8 \mathrm{Ma}$ ), which is also placed nearer to mainland Europe, and most of the other islands appeared when Santa Maria was already 4 Myr old (see Borges \& Brown, 1999). Even considering that Santa Maria was only available for colonization more recently (possibly only $5.5 \mathrm{Ma}$ ) due to an eruptive phase that gave origin to its most recent part (Serralheiro \& Madeira, 1993), this island was the initial land in the current Azores. (2) Alternatively, the proximity of other islands could result in smaller numbers of SIEs than expected by the GDM model. If the gene flow between populations on nearby islands is higher than the threshold necessary for their diversification into distinct lineages, the number of SIEs produced in these islands will be smaller than in more isolated ones. In addition, the proximity of other islands increases the possibility that the species formed on one island are able to colonize others, thus reducing the number of SIEs. As a consequence, a positive relationship between within-archipelago isolation (distance to 
other islands) and the number of SIEs will be expected. Although Whittaker et al. (2008) mention both hypotheses in their prediction number 3, they do not provide any test of their relative importance in comparison to the $\mathrm{ATT}^{2}$ model.

Prediction 4: The relative importance of time, area and isolation as drivers for diversification will vary between different species groups according to their ability to disperse: (1) area and (2) isolation and time will be more important in groups with high and low dispersal abilities, respectively

As in prediction 3, the relative isolation of each island is expected to affect the number of SIEs present. Since the degree of isolation between populations placed at the same sites varies between biological groups according to their dispersal ability, different patterns of diversification should also be expected (see Heaney et al., 2005; Heaney, 2007). SIEs will be positively related to island area in groups with high dispersal ability. In the absence of important limitations for the arrival of different lineages, islands will act as 'passive traps' for these taxa. Therefore, the more area available, the more individuals would be able to reach the island regardless of the distance from the source of colonization, and therefore the higher the probability of the establishment of viable populations of some species, which in the long term could produce new SIEs by anagenetic diversification processes and in situ radiation (increasing cladogenetic diversification). Conversely, isolation and time for speciation will be important issues for groups with low dispersal ability. The limited arrival of lineages from the source of colonization will result in a stronger (and negative) relationship between SIEs and the distance to that source (Santa Maria Island in the case of Azores). Limited dispersal abilities might also result in higher isolation of different populations within the same island, so island age will gain in importance in relation to area as a driver of diversification (see Borges \& Brown, 1999), both as time for speciation and due to the within-island isolation of populations resulting from the increase in heterogeneity along with the geological evolution of the island (see Whittaker et al., 2007, 2008). As before, a simpler version of this prediction is included within the GDM formulation (also within their prediction 3), but its effect is not tested by the proponents (Whittaker et al., 2008).

We evaluate the importance of these four predictions for the arthropod fauna of the Azores, both as a whole and separately for some particular groups, namely all beetles (a highly diverse but more homogeneous group), cavernicolous (and noncavernicolous) species, and species with high and low dispersal abilities. We calculate the number of SIEs per island (both species and subspecies). We use simple generalized linear modelling analyses to examine the effects of several island characteristics and some models (such as $\mathrm{ATT}^{2}$ ) on SIEs, and discuss the results within the framework provided by the general dynamic theory of oceanic island biogeography of Whittaker et al. (2008).

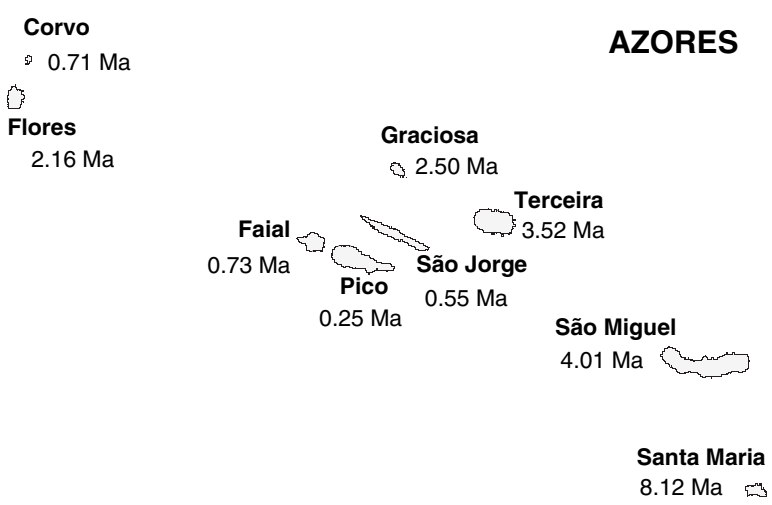

Figure 1 The Azorean islands with indication of the maximum geological ages of each island.

\section{MATERIALS AND METHODS}

The Azores is an isolated archipelago located in the North Atlantic (37-40 $\mathrm{N}, 25-31^{\circ} \mathrm{W}$ ) (Fig. 1) made up of nine islands and some small islets aligned on a west-north-west to east-south-east axis. These islands extend for $c .615 \mathrm{~km}$ across the mid-Atlantic Ridge, which separates the western group (Flores and Corvo) from the central (Faial, Pico, São Jorge, Terceira and Graciosa) and the eastern (São Miguel and Santa Maria) groups. All of the islands are of relatively recent volcanic origin, ranging from 250,000 $\mathrm{yr} \mathrm{BP}$ (Pico) to $8.12 \mathrm{Myr}$ BP (Santa Maria) (Borges \& Brown, 1999; Nunes, 1999). The geostructural environment of the Azores Plateau is dominated by the triple junction of the North American, Eurasian and African lithospheric plates. Unlike the Hawaiian islands, which form a chronologically arranged chain over a stationary hotspot beneath a drifting tectonic plate, the location of the Azorean islands and their individual ages of emergence do not show a linear correlation with their distances to the midAtlantic Ridge. This lack of association between distance and age provides an excellent opportunity to assess the relative importance of island age and geographical distance between islands in determining patterns of colonization and diversification within the archipelago. In addition, the Azores are characterized by high volcanic activity typical of a ridgehotspot interaction (i.e. a hotspot on a slow-moving plate boundary), and present different eruptive styles and patterns of geological evolution (Nunes, 1999). For example, most of the islands have subsidence calderas (e.g. Furnas and Santa Bárbara calderas), a signal of past highly explosive, destructive and acid volcanism of plinian sensu lato type, whereas other islands or volcanic areas (e.g. Santa Maria, São Jorge and Pico) are characterized by basaltic sensu lato fissural volcanism, which is much less explosive.

The number of species native to the Azores is relatively poor due to the high isolation of the archipelago from the mainland (Borges \& Brown, 1999). We obtained data on the presence/absence of native terrestrial arthropods across all Azorean islands from an exhaustive checklist (Borges et al., 2005a). This checklist was created by many taxonomists who 
performed a detailed revision of the taxonomic status of many species, identified many synonyms and improved the list of Azorean arthropods. As a consequence of the exhaustiveness of taxonomic work and the relative poorness of Azorean fauna, this checklist includes virtually all arthropod species native to the Azores and provides an accurate description of their presence or absence on all the islands of the archipelago. Therefore it can be assumed that the data used include all the species pertaining to each one of the categories analysed (see categories below). The two smaller islands (Graciosa and Corvo) were not considered for analyses due to the lack of reliable data on arthropod distribution and to the high impact of human occupation and the resultant disappearance of native forests on these islands (see Borges et al., 2005b). Therefore only seven islands were used in the analyses: Santa Maria, São Miguel, Terceira, São Jorge, Pico, Faial and Flores (Table 1).

We calculated the number of SIEs as the total sum of species and subspecies endemic to a particular island (Table 1; and see Appendix S1 in Supporting Information). Subspecies can be considered as incipient species (see, e.g., Phillimore et al., 2007), so we have defined SIEs at the subspecies level to obtain a finer resolution of the diversification processes, given the relatively poor native fauna of the Azores, the relatively young age of the archipelago and the high quality and exhaustiveness of the taxonomic revision made before the publication of the Borges et al. (2005a) checklist. As islands are unambiguously defined, endemics are the (sub)species restricted to only one island. From an archipelago perspective, taxa occurring on more than one island, but not outside the archipelago, can be considered archipelago endemics but not SIEs, since currently they cannot be assigned to the island(s) of origin. Although the number of SIEs presents some problems as a measure of diversification, it provides the best available approximation to evolutionary dynamics in islands when good quality genetic data are lacking. Consequently, it is commonly used to describe diversification in the recent literature on island biogeography (see Discussion and Whittaker et al., 2008). Contrary to Whittaker et al. (2008), we have considered subspecies designations, counting them in the SIE metrics. This will include taxa that are undergoing a process of speciation (see O’Brien \& Mayr, 1991; Phillimore et al., 2007), which is important to consider in a young archipelago such as the Azores. To explore the above-mentioned hypotheses, we studied the number of SIEs of six different groups of species: 1 All arthropods ( $\mathrm{SIE}_{\text {art }}$ ), to have a picture of the overall diversification processes occurring in the archipelago.

2 All beetles $\left(\mathrm{SIE}_{\mathrm{col}}\right)$, to examine diversification patterns in a highly diverse monophyletic group.

3 Cavernicolous species $\left(\operatorname{SIE}_{\mathrm{cav}}\right)$, calculated as all SIEs showing adaptation to cave environments.

4 Non-cavernicolous species ( $\mathrm{SIE}_{\text {ncav }}$ ), those species without special adaptations to cave environments (i.e. the rest of the SIE species = epigean species).

5 Taxa with high dispersal ability $\left(\mathrm{SIE}_{\mathrm{Hdis}}\right)$, including all SIEs that present active dispersal mechanisms, such as butterflies, winged beetles or spiders (which disperse actively by means of ballooning).

Table 1 Number of single-island endemics (SIEs) per island and scores of the island characteristics used in the analyses (see text for SIE and variable abbreviations). When relevant, units are given in brackets. Latitude and longitude refer to the centre of the island, and are given in decimal degrees north and west, respectively. Maximum altitude, habitat diversity (HD) and distance to mainland were included, in spite of not being used for the analyses, due to their wide usage in the literature on island biogeography.

\begin{tabular}{|c|c|c|c|c|c|c|c|}
\hline & Santa Maria & São Miguel & Terceira & São Jorge & Pico & Faial & Flores \\
\hline \multicolumn{8}{|l|}{ Single-island endemics } \\
\hline SIE $_{\text {art }}$ & 16 & 34 & 15 & 7 & 13 & 10 & 13 \\
\hline $\mathrm{SIE}_{\text {col }}$ & 12 & 9 & 4 & 2 & 6 & 4 & 3 \\
\hline $\operatorname{SIE}_{\mathrm{cav}}$ & 0 & 1 & 3 & 3 & 4 & 2 & 0 \\
\hline $\mathrm{SIE}_{\text {ncav }}$ & 16 & 33 & 12 & 4 & 9 & 8 & 13 \\
\hline SIE $_{\text {Hdis }}$ & 5 & 20 & 6 & 4 & 6 & 5 & 9 \\
\hline SIE $_{\text {Ldis }}$ & 11 & 13 & 6 & 0 & 3 & 3 & 4 \\
\hline \multicolumn{8}{|l|}{ Island characteristics } \\
\hline Latitude & 36.9 & 37.7 & 38.7 & 38.7 & 38.5 & 38.6 & 39.4 \\
\hline Longitude & 25.1 & 25.5 & 27.2 & 27.9 & 28.2 & 28.5 & 30.9 \\
\hline Area $\left(\mathrm{km}^{2}\right)$ & 97 & 757 & 402 & 246 & 433 & 172 & 142 \\
\hline Maximum altitude (m a.s.l.) & 587 & 1103 & 1023 & 1053 & 2351 & 1043 & 915 \\
\hline Geological age (Ma) & 8.12 & 4.01 & 3.52 & 0.55 & 0.25 & 0.73 & 2.90 \\
\hline Ncav & 0 & 22 & 58 & 14 & 100 & 7 & 0 \\
\hline Lcav (m) & 455 & 2770 & 12,113 & 847 & 23,872 & 263 & 75 \\
\hline $\mathrm{HD}$ & 2 & 8 & 12 & 3 & 8 & 5 & 9 \\
\hline Distance to mainland $(\mathrm{km})$ & 1588 & 1584 & 1764 & 1832 & 1860 & 1908 & 2152 \\
\hline $\operatorname{Dmin}(\mathrm{km})$ & 81 & 81 & 38 & 18 & 6 & 6 & 220 \\
\hline Dmean $(\mathrm{km})$ & 263.7 & 192.7 & 133.3 & 115.7 & 119.4 & 138.0 & 305.1 \\
\hline Dsmr $(\mathrm{km})$ & 0 & 81 & 248 & 285 & 297 & 348 & 587 \\
\hline
\end{tabular}


6 Taxa with low dispersal ability $\left(\mathrm{SIE}_{\mathrm{Ldis}}\right)$, which include all SIEs without active dispersal mechanisms excluding cavernicolous species; these species include collembolans, flightless beetles, millipedes and pseudoscorpions.

Thus, $\operatorname{SIE}_{\text {art }}$ is equal to $\mathrm{SIE}_{\mathrm{cav}}+\mathrm{SIE}_{\text {ncav }}$, or to $\mathrm{SIE}_{\mathrm{cav}}+$ $\mathrm{SIE}_{\mathrm{Hdis}}+\mathrm{SIE}_{\mathrm{Ldis}}$.

Seven variables accounting for island characteristics were used as predictors of SIEs (see Table 1), as follows. (1) Area accounts for the size of the island, which determines opportunity for speciation through isolation of populations within the island as well as its carrying capacity (see Whittaker et al., 2008). (2) Geological age (age; extracted from Nunes, 1999) accounts for the time available for speciation. This is highly dependent on the correct estimate of the geological times for the aerial part of the islands. Here we did not take into account the potential destructive forces of recent explosive and destructive volcanism on some of the islands, which would imply the reduction of the maximum estimated ages for islands with recent calderas (e.g. Flores, Faial, Terceira and recent part of São Miguel). However, as there is still no agreement on which age to use for most of those islands we kept the maximum ages of aerial rocks as given by Nunes (1999). (3) Number of caves (Ncav; number of lava tubes and volcanic pits) and (4) length of caves (Lcav; total length of volcanic caves within the island) account for the opportunities for speciation of cavernicolous species through the isolation of their populations (extracted from Pereira et al., in press). (5) Distance to the nearest island (Dmin) and (6) mean distance to the other islands (Dmean) account for the isolation of the island and the consequent opportunities for speciation due to isolation from the populations on other islands within the archipelago. (7) Distance to Santa Maria Island (Dsmr) accounts for the distance to the general source for the current evolutionary pool of the archipelago; the oldest island, Santa Maria is the unique remnant of the former configuration of the Azorean archipelago (that existed before 8 Ma; Nunes, 1999) and has acted as a refuge for older biota (Borges \& Brown, 1999), so it can be assumed that most lineages have recolonized the rest of the islands from there.

Most island descriptors used here as predictors are expected to be collinear (see Discussion). Due to this, when two closely related variables (e.g. Dmin and Dmean) presented significant relationships with SIEs, we assumed that the best predictor (the one accounting for the higher explained variability and the smallest Akaike information criterion value) from the analyses (see below) provides the most parsimonious explanation of the relationship and therefore is most likely to be a determinant of SIEs. This conservative approach does not allow the identification of potentially explanatory interactions between variables, but we have adopted it to minimize the risk of type I errors (i.e. accepting as true spurious correlations that do not correspond to causal relationships), which is quite likely given the small number of cases available. In addition, three variables that are commonly used as surrogates for habitat diversity and isolation were excluded from the analyses due to their high collinearity with other relevant variables and their low explanatory power. Maximum altitude of the island was discarded because of its correlation with island age (the youngest islands are also the highest). Forest diversity (i.e. the number of different types of natural forests; see Ribeiro et al., 2005; Borges et al., 2006) covaries also with maximum altitude (the highest islands also host more types of forests; see Heaney et al., 2005). Finally, distance to the mainland (the European continent) was also discarded because of its high correlation with Dsmr, which is also the island placed nearest to Europe and can be considered as the main source of colonizers for the rest of the islands (see also discussion in Prediction 3 above). The effect of these three variables was examined (see below), but their importance was much smaller than their counterparts (age and Dsmr), being marginal in the case of altitude and forest diversity (not shown).

The explanatory capacity of the variables was assessed through a GLM, using deviance as a measure of explained variability, and the $F$ statistic to assess significance (McCullagh \& Nelder, 1989). The number of SIEs is a count variable, so it was assumed to have a Poissonian error distribution (Dobson, 1999), which was confirmed after a visual examination of the histograms (tests on regression fitting were not feasible due the small number of degrees of freedom). The variables were linked to the predictors using a $\log$ function (i.e. equivalent to semi-log models in common regressions), following the rationale of Whittaker et al. (2008) and most previous literature. Thus, no previous log transformation of area, altitude, age and the three distance variables was made, since such a log relationship was included within the assumptions of the GLM analyses. All predictors were related one by one to the SIE scores of each group of species in univariate analyses. The statistical significance of the change of deviance models was set to a 0.1 level for these analyses, since significance levels that were too restrictive could hamper the detection of important but less strong relationships due to the small number of cases.

In addition, some multivariate models were also tested, involving the different abovementioned hypotheses (e.g. the $\mathrm{AT}$ and $\mathrm{ATT}^{2}$ models) as well as additional possible interactions between predictors appearing after the results of the univariate analyses. Apart from the overall significance of the model, the significance of each variable within these multivariate models was assessed using the Akaike information criterion (AIC) and the Wald statistic within the Best Subsets option of statistica (StatSoft Inc., 2003; see also McCullagh \& Nelder, 1989). In this case, we used a significance level of 0.05 to accept model parameters to avoid the spurious selection of overparametrized models, although parameters significant at $P<0.1$ are also highlighted. Finally, we assessed the relative performance of the different models using the small-sample second-order bias correction of the Akaike information criterion $\left(\mathrm{AIC}_{\mathrm{c}}\right)$, as recommended by Burnham \& Anderson (2002). The models showing the lowest $\mathrm{AIC}_{\mathrm{c}}$ values are the most informative, and therefore the most likely to have a consistent relationship with the dependent variable, regardless of the variability they explain. 


\section{RESULTS}

In total, 108 SIEs (40 from Coleoptera), out of 267 endemic arthropod species and subspecies (updated from Borges et al., 2005a), have been described for the Azores to date; 13 of the SIEs are cavernicolous, and of the rest, 55 pertain to groups with high dispersal ability and 40 to groups of low dispersal ability (Table 1 and see Appendix S1). In general, island age was significantly related to the number of SIEs of most groups (except SIE $_{\text {Hdis; }}$ Table 2), showing positive (sometimes humpshaped) relationships except in the case of $\operatorname{SIE}_{\text {cav }}$ (see Fig. 2). The effect of island area was generally less important, except for groups of high dispersal ability, being unrelated or marginally related to $\mathrm{SIE}_{\mathrm{col}}$, $\mathrm{SIE}_{\mathrm{cav}}$ or $\mathrm{SIE}_{\mathrm{Ldis}}$. In addition to time and area, isolation also appears as a relevant factor for all groups except $\mathrm{SIE}_{\mathrm{Hdis}}$ (marginally in the case of $\mathrm{SIE}_{\text {ncav }}$ ), in most cases showing strong negative relationships with the distance to Santa Maria, except in the case of cavernicolous species (Fig. 2), where the isolation from nearby islands in the archipelago (Dmin and, especially, Dmean) stands out as the most important determinant (although with negative effect) of $\mathrm{SIE}_{\mathrm{cav}}$ (Table 2). SIE $\mathrm{Cav}_{\mathrm{c}}$ was also marginally related to the number and length of caves in the island. Within the complex models, AT provided the most parsimonious explanation (higher explained variability, significant model parameters and smaller $\mathrm{AIC}_{\mathrm{c}}$ values) for all the arthropods as a whole (92\% of explained variation) as well as for non-cavernicolous species (85\%) and groups with low dispersal ability (81\%), being nonsignificant or failing to provide significant parameters in the other three groups (Table 2).

\section{DISCUSSION}

Why some islands within an archipelago and some of the taxa inhabiting such an archipelago present markedly higher diversification rates are questions that are difficult to answer adequately in a simple way. For this reason, Whittaker et al.'s (2008) GDM of oceanic island biogeography is unlikely to provide a precise explanation for the diversification patterns in all groups and all oceanic archipelagos world-wide. Rather, its main value lies in providing a heuristic framework to study and understand these patterns, thus improving former descriptions of the well-known fact that diversity and diversification in oceanic islands are (at least partly) a matter of area and time. Either the groups fitting closely to the $\mathrm{ATT}^{2}$ model or the exceptions to GDM predictions will provide insight on the causes of diversification in oceanic archipelagos. For example, land snails, the only Azorean group whose diversification was evaluated by Whittaker et al. (2008) (in their study, plants were only studied in terms of richness due to their limited diversification), did not show the hump-shaped pattern predicted by the GDM. As commented on above, the particularities and young age of the Azorean islands will result in a better fit of an AT model for most groups, a prediction within the bounds of the GDM theory (see also Prediction 1 below). In this work, we use GDM as the basis for the study of arthropod diversification within the Azores, the most speciesrich and diverse group (with c. 50\% of all terrestrial animal and plant species; see Borges et al., 2005b). The investigation of different groups apart from the totality of the arthropods (beetles, cave-adapted species and species with high and low dispersal abilities) allowed an exploration of the effects of some factors within the framework of the GDM theory (Whittaker et al., 2008), which resulted in a significant gain in our understanding of the diversification of arthropods in the Azores. The understanding of island diversification patterns in dynamic and complex volcanic archipelagos will be improved with a more detailed hypothesis driven by splitting up the large groups that were previously investigated with the GDM.

\section{Effectiveness of the area + time model to explain overall arthropod diversification (Prediction 1)}

Speciation (i.e. diversification through cladogenesis and anagenesis) takes time. Therefore, older islands have the potential to generate more endemic species (see Borges \& Brown, 1999); as some of these species persist over the long term, older islands usually host older species (Heaney, 2007). Due to this, the hypothetical island equilibrium diversity would result from a balance between speciation and extinction rates (Rosenzweig, 2001; Stephens \& Wiens, 2003; Erwin, 2005). In addition, larger islands should present higher speciation rates (MacArthur \& Wilson, 1963, 1967). However, in situ speciation within an archipelago results from a number of different processes (see review in Whittaker \& Fernández-Palacios, 2007), so the relationship between diversification and time is not a simple one. Neither is the relationship between speciation and area simple (Losos \& Schluter, 2000). Moreover, in oceanic archipelagos the area of a given island varies with time. The integration of the geological evolution of the island with the complexity of diversification processes results in a highly dynamic view of diversity through time (Heaney, 2000; Stuessy, 2007; Whittaker et al., 2007). The theoretical framework provided by Whittaker et al.'s (2008) GDM allows examination of these complex processes with an integrative perspective.

Our results provide some support for the hypothesis of diversification on the Azores being a product of area and time, mostly following the linear shape expected in our Prediction 1. The AT model was the most parsimonious explanation for the number of SIEs of all arthropods, non-cavernicolous species and species of low dispersal ability (but not cave-adapted species). In these three cases, the relationship with time also shows a hump-shaped trend, partly because of the large area of São Miguel. For a wide range of species, diversification events increase linearly with time for the younger islands, with a subsequent increasing number of SIEs. Recent islands (e.g. Pico) present a more homogeneous landscape than older islands, which together with the limited time for speciation result in lower adaptive radiation. As the islands become old and eroded (e.g. Terceira, São Miguel and Santa Maria), the landscape changes to become more diversified (e.g. flattened 


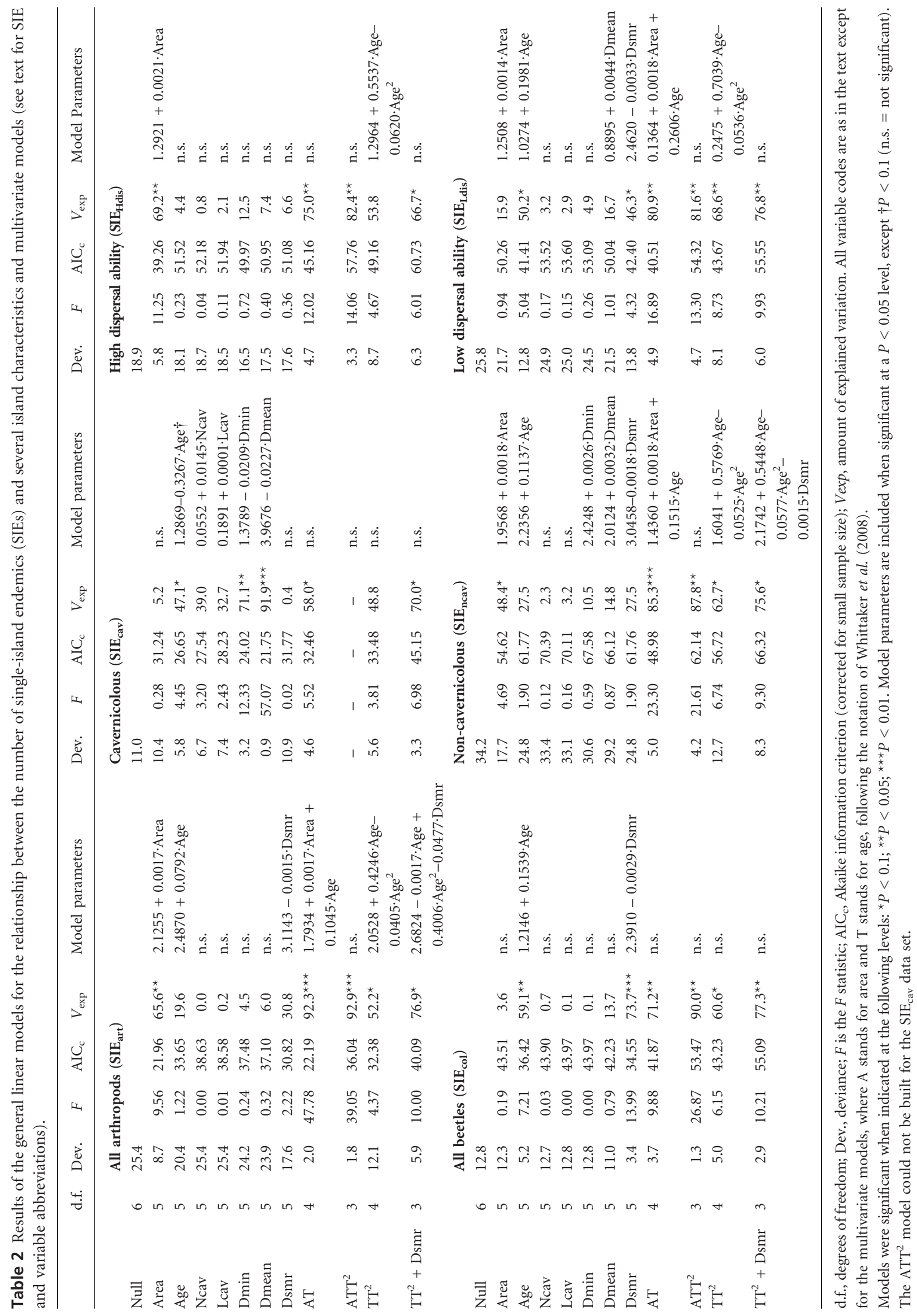




\section{All arthropods}
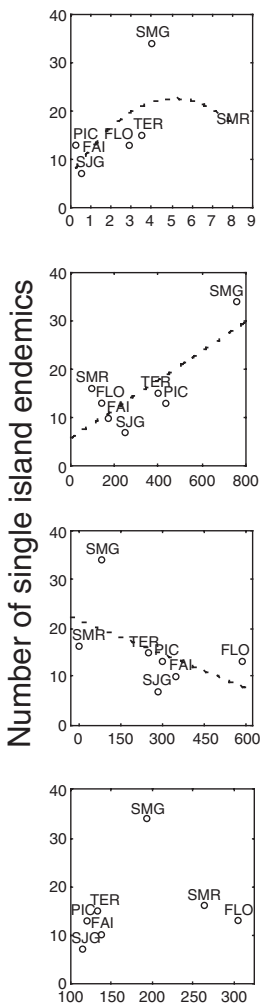

Beetles
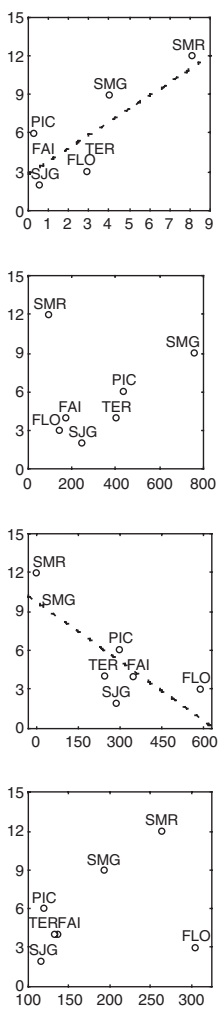
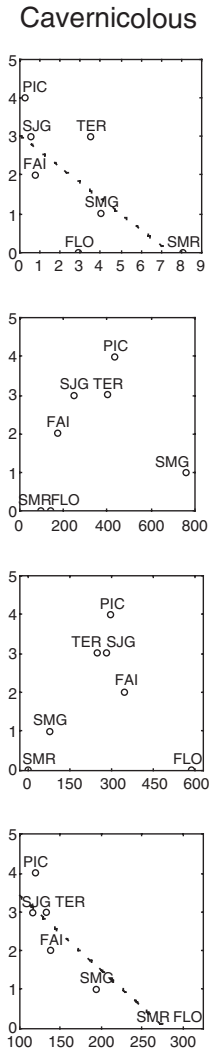

Noncavernicolous
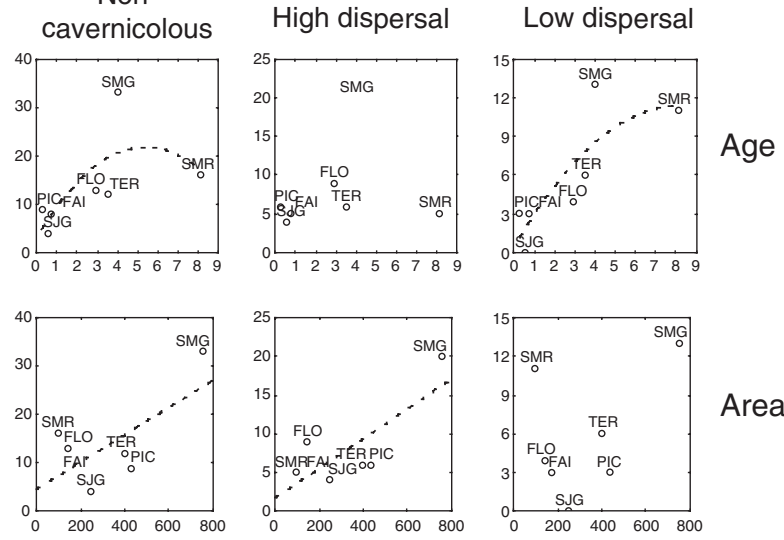

Area
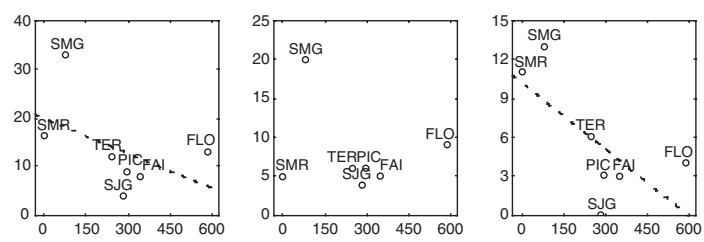

Dist.

Santa

Maria
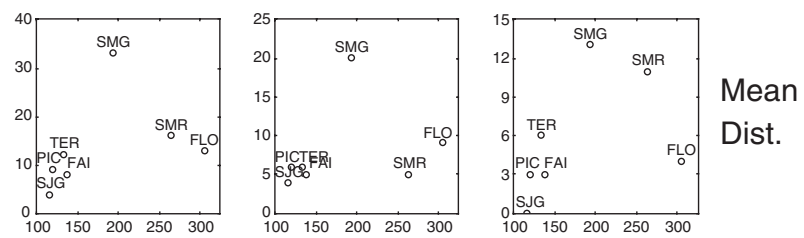

Figure 2 Relationship between the number of single-island endemics of each group of species analysed and several characteristics of the island ( $x$-axis): geological age (Age, Ma), area $\left(\mathrm{km}^{2}\right)$, distance to the oldest island (Dist. Santa Maria, $\mathrm{km}$ ), and mean distance to the rest of the islands (Mean Dist., km). The shape and sign of the relationships are indicated when significant by a discontinuous line (see Table 1). Island names are abbreviated as follows: SMR, Santa Maria; SMG, São Miguel; TER, Terceira; SJG, São Jorge; PIC, Pico; FAI, Faial; FLO, Flores.

areas, volcanic cones with differential erosion, more types of soil available for different plant communities, etc.), increasing the niches available for colonization and diversification of species. The reduction in the number of SIEs produced by immigration to other islands and extinction of some endemic lineages predicted by the GDM model is partially observed for Santa Maria for most groups (but not for beetles, see below).

In the other three groups analysed, the AT model was discarded due to its poorer performance according to $\mathrm{AIC}_{\mathrm{c}}$ and the low significance of its parameters. These three groups are good examples of the departure from the raw GDM predictions (as formulated for younger archipelagos in our Prediction 1) due to the effects that led to our three additional predictions. Cavernicolous taxa follow our Prediction 2, and the species with high dispersal ability do so for our Prediction 4. More surprising is the case of beetles; a pattern similar to the one found for all arthropods was expected for a group with a high diversity of adaptations. However, the number of lineages of beetles that have actually diversified within the Azores is relatively small (see Appendix S1), and most of them occur on Santa Maria, so the number of SIEs shows a strong dependence on isolation from the oldest island (our Prediction 3), and is also relatively independent of area (see discussion below).

\section{Early diversification of cavernicolous taxa (Prediction 2)}

The production of SIEs through diversification processes is not exclusive to old islands. The most recent islands also present some SIEs originating from nearly the beginning of the island ontogeny. A particular case is that of the species adapted to life in caves. Their particular life history results in radically different diversification patterns.

On the one hand, since younger islands have a diverse set of habitats of volcanic origin (i.e. lava flows, lava tubes, volcanic pits and pit-caves) the greater opportunities for speciation occur during the early stages of island evolution (see Borges et al., 2007). Our results support the prediction that young islands host more cavernicolous SIEs than expected from the GDM model. In fact, the relationship between the number of SIEs and island age is negative, although marginally significant. The relatively low fit (almost $50 \%$ of explained variability) of this relationship is related to the large number of troglobites present on Terceira and, to a lesser extent São Miguel, a consequence of the recent episodes of volcanism in these two older islands. In spite of the general trend of extinction of cavernicolous SIEs as islands become older, endemic 
troglobites from these islands support Heaney's (2007) hypothesis that some species persist for very long periods on oceanic islands. The troglobite Thalassophilus azoricus (endemic to São Miguel) is the only eyeless ground beetle in the Azores, showing a higher degree of troglomorphism than any of the cave-adapted Azorean Trechus (Borges et al., 2007). This could be explained by the older age of São Miguel (4 Ma) compared with that of the other Azorean islands where cavernicolous species occur (ranging from 0.25 Ma for Pico to 3 Ma for Terceira). A similar case occurs in the Canary Islands where three hypogean Trechinae occurring in Tenerife (12 Ma) are completely eyeless, while those from the younger islands of La Palma (2 Ma) and El Hierro (1 Ma) still present merely reduced eyes (Machado, 1988, 1990).

On the other hand, the length and characteristics of the cave system provide better measures of habitat diversity than surface area for these species. Although the relationships between SIE $_{\text {cav }}$ and either number or length of caves were not significant, they were more explanatory than area, accounting for roughly a third of the variation in both cases, thus supporting to some extent the second part of our Prediction 2. Younger islands have an important number of pristine cave habitats, usually isolated in different cave systems within the island. Therefore, if the diversification of cavernicolous species could occur at relatively fast rates, taking into account the highly limited dispersal ability of troglobites, the limiting factor for the development of cavernicolous SIEs will be the number of propagules colonizing the island during the first stages of its development, rather than the number or length of these caves. Contrary to the above-mentioned examples of progressive adaptation of highly persistent species, there are also cases of more specialized troglobites occurring on younger islands (see Borges et al., 2007), which implies a faster rate of diversification, possibly due to opportunity-driven evolutionary processes (e.g. Gillespie, 2004; Levin, 2004). The most relevant predictors of the number of cavernicolous SIEs were those accounting for isolation from nearby islands, providing support for our Prediction 3 (see discussion below).

\section{Isolation from the source of colonizers and differences in dispersal ability result in different determinants of diversification (Predictions 3 and 4)}

Long-distance dispersal of terrestrial organisms to islands over large extents of ocean is now thought to be a rare event at short time-scales, but a common one during a longer geological span of time (Heaney, 2007) or even at smaller time-scales (see Nathan, 2005). Yet, isolation arises as an important factor in shaping island biotas (Heaney et al., 2005; Beck et al., 2006a,b), due to two related phenomena acting in opposite directions. More isolated islands will have lower immigration rates and an absence of constant gene flow that might result in a higher frequency of founder effects generating new species on these islands (but see Clegg et al., 2002). Conversely, diversification needs some species to colonize the island and act as 'nurses' for the generation of new species (i.e. the so-called 'nursery effect'; see Rosenzweig, 2001, 2003). Therefore, although isolation facilitates the appearance of new SIEs [resulting in our Prediction 3(2)], it might also reduce the number of SIEs if the number of lineages colonizing the island is limited [our Prediction 3(1)]. This is also inherent in the GDM model (Whittaker et al., 2008; R. J. Whittaker, personal communication).

Our results provide strong support for the prediction that SIEs will show a negative relationship with the distance from the main source of lineages [Prediction 3(1)] in most cases. Taxa with low dispersal ability, particularly beetles, showed strong negative relationships with the distance to Santa Maria, the oldest island and reservoir of lineages either coming from the mainland or remaining from the older archipelago. Such negative relationships were also nearly significant for the allarthropod and non-cavernicolous SIE data sets. The extreme case of Coleoptera (Dsmr accounts for almost 75\% of variation in $\left.\mathrm{SIE}_{\mathrm{col}}\right)$ is probably related to the limited dispersal ability and relatively low diversification rates of the most speciose beetle genera (i.e. Tarphius and Trechus). Therefore, the number of colonization events of these taxa is limited, both from the mainland and from within the archipelago. For example, all eight endemic Tarphius species are the consequence of a single old colonization event to Santa Maria (Amorim, 2005). Three of these species are endemic to Santa Maria, arising due to local radiation. However, Santa Maria was the only island where Tarphius has had sufficient time to radiate into new species; the other five species are the consequence of a stepping-stone process, originating in Santa Maria and occurring on more than one island. For groups with higher dispersal ability and/or diversification rates, this process would be less important in shaping SIE patterns (see Gillespie, 2004).

Contrary to our expectations, the isolation of nearby islands did not have a significant positive effect on the SIEs of any group, thus rejecting our Prediction 3(2). Interestingly, in the Azores the number of duplicate island endemics (i.e. species and subspecies occurring in two islands) within the arthropods is relatively small. Non-cavernicolous and taxa with a low dispersal ability were the only groups showing positive relationships with Dmean and Dmin, but these relationships were poorly explanatory in both cases. Only $17 \%$ of the species not endemic to a single island (i.e. non-SIE) are duplicates, implying that species colonizing a nearby island are usually able to spread relatively easily to other islands. Yet, $70 \%$ of these few duplicates occur in one of the three older (and easternmost) islands (Santa Maria, São Miguel and Terceira), which together constitute the source of the founding lineages for the most recent islands located further west (see above).

The only case where the variables accounting for the distance to nearby islands were explanatory was cavernicolous fauna, showing strong negative relationships with the number of SIEs (more than $90 \%$ in the case of Dmean). Troglobite species represent the most extreme cases of low dispersal ability. In addition, their diversification is constrained by the possibility of the arrival or presence on islands of young age of forest epigean species able to colonize the underground environment. Both 
limitations result in the decay of colonization events occurring at a much shorter distance for these species, since only nearby islands would be able to provide a significant number of colonizers within a reasonable time frame. Therefore, in this case the main sources of colonizers are nearby islands, and the strong negative relationship of $\mathrm{SIE}_{\mathrm{cav}}$ with Dmean and Dmin provides additional support for Prediction 3(1).

Interestingly, the taxa with high dispersal ability are the only group not showing any relationship at all between the number of SIEs and isolation. Here, area was the most parsimonious explanation for their patterns of diversification [thus confirming our Prediction 4(1)]. Instead, the SIEs of taxa with low dispersal ability showed the closest fit to island age; in this case, the AT model provided the best explanation of their patterns [confirming our Prediction 4(2)]. Other studies have reported differences in diversity and diversification patterns arising from differences in dispersal ability (e.g. Heaney et al., 2005), even within groups of high dispersal ability (Beck et al., 2006b). In the case of the Azores, most groups show relatively higher dispersal ability, so a number of new taxa do not remain as SIEs since they colonize other islands. In this case, area, and thus opportunity for within-island adaptive radiations, appears as the most important factor for the existence of SIEs. For species with low dispersal ability, time stands out as a necessary condition for diversification. These taxa require a sufficient accumulation of colonization events on each island to allow the in situ evolution of species and to accumulate important numbers of SIEs over the long term.

\section{Concluding remarks}

As in the case of MacArthur \& Wilson's model, the aim of generality and the relative simplicity of Whittaker et al.'s (2008) GDM of oceanic island biogeography necessarily results in some limitations. As the proponents of GDM recognize (R. J. Whittaker and K. Triantis, personal communication), it is impossible to develop a predictive model of island biogeography that is both general and highly precise. Rather, its value relies in the possibility of integrating different hypotheses and deviations from its general predictions into a general framework. We believe that some of the recent hypotheses on island biogeography, such as the 'diversity-driven speciation hypothesis' of Emerson \& Kolm (2005a) or the energy-based global model of Kalmar \& Currie (2006) (both reviewed by Whittaker \& Fernández-Palacios, 2007), would be better understood within the framework of the GDM proposed by Whittaker et al. (2007, 2008). The oversimplified descriptions of the evolutionary processes going on within the archipelagos and of the species-environment relationship provided by the GDM may be complemented in the future with more precise definitions coming from the developments in these two fields. Nevertheless, our results show that successful predictions can be derived by adapting the GDM model to the characteristics of the archipelago under study and its biota.

Our analyses necessarily present some problems common to most work on island biogeography, such as the small number of cases (seven islands in our case) or collinearity among the descriptors of island characteristics. These drawbacks result in a lower explanatory power and make the discrimination of true and spurious effects very difficult (e.g. the possible collinearity between energy and isolation measures in Kalmar \& Currie, 2006; mentioned by Whittaker, 2006). We compensate for these drawbacks by discarding some collinear variables before the analyses, carrying out three different validations (on the effects, on the parameters and on the information provided by each one of the concurrent models) and, more importantly, testing the specific predictions resulting from current knowledge about the evolution of island biotas. This conservative approach does not permit us to evaluate the effect of certain variables that have been commonly used as predictors in island biogeography, such as island altitude (see, e.g., Pereira et al., 2007). Although it could be used as a surrogate for habitat heterogeneity, the relationship of altitude with this factor is highly variable, and therefore it should be used with caution (Triantis et al., 2008), given that its explanatory power is usually lower than more direct measures of area and/or habitat heterogeneity (Triantis et al., 2008; our results). Nevertheless, using SIEs to measure diversification is also problematic (see debate in Cadena et al., 2005; Emerson \& Kolm, 2005a,b, 2007a,b; Kiflawi et al., 2007; Whittaker et al., 2007; Birand \& Howard, 2008; Gruner et al., 2008). However, the number of SIEs provides a simple metric of evolutionary dynamics (Whittaker et al., 2008), especially in the absence of good-quality data on the genetic divergence and phylogeny of large groups of taxa (see also Peck et al., 1999; Emerson \& Kolm, 2005a, 2007a; Whittaker et al., 2007). The problems arising from the use of SIE data are mainly due to the colonization of new islands by species that originated within a given island of the archipelago. Although this might hamper the description of the magnitude of diversification within an island, especially for groups of high dispersal ability, its effects on the number of SIEs can be identified and predicted.

These problems notwithstanding, our work identifies the expectations for patterns of diversification for young archipelagos that can be derived from the GDM model. Moreover, we clarify the role of isolation within the GDM framework, formulating some specific predictions and identifying the patterns that derive from colonization processes, at least in the earlier stages of island development. In addition, we identify where and how some exceptions to the GDM might appear for some specific groups of species, according to their life-history traits and environmental requirements and their relationship with the geological evolution of islands. As a general conclusion, the overall patterns of arthropod diversification on the Azores are consistent with the framework provided by the GDM when adapted to the young age of the archipelago. Some arthropod groups depart from the general predictions of the model, but their behaviour can be integrated easily into the GDM by accounting for their particular characteristics. Nevertheless, the role of isolation was crucial in accounting for variation in our data and for explaining diversification processes, remaining as a factor of central importance for any hypothesis about the diversity of island biotas. 


\section{ACKNOWLEDGEMENTS}

We are indebted to Rob Whittaker and Kostas Triantis for their extensive comments and discussion. We also wish to thank Isabel Amorim, João Carlos Nunes, Ally Phillimore, Lawrence Heaney and several anonymous referees for their comments and advice, as well as Alison Neilson for her English review, and all the people involved in sampling and digitizing all the information currently stored in the ATLANTIS-Açores data base. This work is part of the projects ATLANTICO and BIONATURA - INTERREG IIIB. J.H. was also supported by the Portuguese FCT grant BPD/20809/2004, by UA-CITA A, and by the UK Natural Environment Research Council.

\section{REFERENCES}

Amorim, I.R. (2005) Colonization and diversification on oceanic islands: forest Tarphius and cave-dwelling Trechus beetles of the Azores. PhD Thesis, Department of Ecology and Evolutionary Biology, University of California, Los Angeles.

Beck, J., Kitching, I.J. \& Linsenmair, K.E. (2006a) Determinants of regional species richness: an empirical analysis of the number of hawkmoth species (Lepidoptera: Sphingidae) on the Malesian archipelago. Journal of Biogeography, 33, 694-706.

Beck, J., Kitching, I.J. \& Linsenmair, K.E. (2006b) Wallace's line revisited: has vicariance or dispersal shaped the distribution of Malesian hawkmoths (Lepidoptera: Sphingidae)? Biological Journal of the Linnean Society, 89, 455-468.

Birand, A. \& Howard, D.J. (2008) The relationship between proportion of endemics and species diversity on islands: expectations from a null model. Ecography, 31, 286-288.

Borges, P.A.V. \& Brown, V.K. (1999) Effect of island geological age on the arthropod species richness of Azorean pastures. Biological Journal of the Linnean Society, 66, 373-410.

Borges, P.A.V., Vieira, V., Dinis, F., Jarroca, S., Aguiar, C., Amaral, J., Aarvik, L., Ashmole, P., Ashmole, M., Amorim, I.R., André, G., Argente, M.C., Arraiol, A., Cabrera, A., Diaz, S., Enghoff, H., Gaspar, C., Gisbert, H.M., Gonçalves, P., Lopes, D.H., Melo, C., Mendonça, E.P., Mota, J.A., Oliveira, O., Oromí, P., Pereira, F., Pombo, D.T., Quartau, J.A., Ribeiro, S.P., Rodrigues, A.C., Santos, A.M.C., Serrano, A.R.M., Simões, A.M.A., Soares, A.O., Sousa, A.B., Vieira, L., Vitorino, A. \& Wunderlich, J. (2005a) List of the arthropods (Arthropoda). A list of the terrestrial fauna (Mollusca and Arthropoda) and flora (Bryophyta, Pteridophyta and Spermatophora) from the Azores (ed. by P.A.V. Borges, R. Cunha, R. Gabriel, A.F. Martins, L. Silva and V. Vieira), pp. 163-221. Direcção Regional de Ambiente and Universidade dos Açores, Horta, Angra do Heroísmo and Ponta Delgada.

Borges, P.A.V., Cunha, R., Gabriel, R., Martins, A.F., Silva, L., Vieira, V., Dinis, F., Lourenço, P. \& Pinto, N. (2005b) Description of the terrestrial Azorean biodiversity. A list of the terrestrial fauna (Mollusca and Arthropoda) and flora (Bryophyta, Pteridophyta and Spermatophora) from the Azores (ed. by P.A.V. Borges, R. Cunha, R. Gabriel, A.F.
Martins, L. Silva and V. Vieira), pp. 21-68. Direcção Regional de Ambiente and Universidade dos Açores, Horta, Angra do Heroísmo and Ponta Delgada.

Borges, P.A.V., Lobo, J.M., Azevedo, E.B., Gaspar, C., Melo, C. \& Nunes, V.L. (2006) Invasibility and species richness of island endemic arthropods: a general model of endemic vs. exotic species. Journal of Biogeography, 33, 169-187.

Borges, P.A.V., Oromí, P., Serrano, A.R.M., Amorim, I.R. \& Pereira, F. (2007) Biodiversity patterns of cavernicolous ground-beetles and their conservation status in the Azores, with the description of a new species: Trechus isabelae n. sp. (Coleoptera, Carabidae, Trechinae). Zootaxa, 1478, 21-31.

Burnham, K.P. \& Anderson, D.R. (2002) Model selection and inference: a practical information-theoretical approach, 2nd edn. Springer-Verlag, New York.

Cadena, C.D., Ricklefs, R.E., Jiménez, I. \& Bermingham, E. (2005) Ecology: is speciation driven by species diversity? Nature, 438, E1-E2.

Clegg, S.M., Degnan, S.M., Kikkawa, J., Moritz, C., Estoup, A. \& Owens, I.P.F. (2002) Genetic consequences of sequential founder events by an island-colonizing bird. Proceedings of the National Academy of Sciences USA, 99, 8127-8132.

Coyne, J.A. \& Price, T.D. (2000) Little evidence for sympatric speciation in island birds. Evolution, 54, 2166-2171.

Culver, D.C. (2001) Subterranean ecosystems. Encyclopedia of biodiversity, Vol. 5 (ed. by S.A. Levin), pp. 527-540. Academic Press, San Diego.

Dobson, A. (1999) An introduction to generalized linear models. Chapman \& Hall/CRC, London.

Emerson, B.C. (2002) Evolution on oceanic islands: molecular phylogenetic approaches to understanding pattern and process. Molecular Ecology, 11, 951-966.

Emerson, B.C. \& Kolm, N. (2005a) Species diversity can drive speciation. Nature, 434, 1015-1017.

Emerson, B.C. \& Kolm, N. (2005b) Ecology: Is speciation driven by species diversity? (Reply). Nature, 438, E2.

Emerson, B.C. \& Kolm, N. (2007a) Response to comments on Species diversity can drive speciation. Ecography, 30, 334-338.

Emerson, B.C. \& Kolm, N. (2007b) Species diversity can drive speciation: reply. Ecology, 88, 2135-2138.

Erwin, D.H. (2005) Seeds of diversity. Science, 308, 1752-1753. Gillespie, R.G. (2002) Biogeography of spiders on remote oceanic islands of the Pacific: archipelagoes as stepping stones? Journal of Biogeography, 29, 655-662.

Gillespie, R.G. (2004) Community assembly through adaptive radiation in Hawaiian spiders. Science, 303, 356-359.

Gillespie, R.G. \& Roderick, G.K. (2002) Arthropods on islands: colonization, speciation, and conservation. Annual Review of Entomology, 47, 595-632.

Gruner, D.S., Gotelli, N.J., Price, J.P. \& Cowie, R.H. (2008) Does species richness drive speciation? A reassessment with the Hawaiian biota. Ecography, 31, 279-285.

Heaney, L.R. (2000) Dynamic disequilibrium: a long-term, large-scale perspective on the equilibrium model of island biogeography. Global Ecology and Biogeography, 9, 59-74. 
Heaney, L.R. (2007) Is a new paradigm emerging for oceanic island biogeography? Journal of Biogeography, 34, 753-757.

Heaney, L.R., Walsh, J.S. \& Peterson, A.T. (2005) The roles of geological history and colonization abilities in genetic differentiation between mammalian populations in the Philippine archipelago. Journal of Biogeography, 32, 229247.

Kalmar, A. \& Currie, D.J. (2006) A global model of island biogeography. Global Ecology and Biogeography, 15, 72-81.

Kiflawi, M., Belmaker, J., Brokovich, E., Einbinder, S. \& Holzman, R. (2007) Species diversity can drive speciation: comment. Ecology, 88, 2132-2135.

Levin, D.A. (2004) The ecological transition in speciation. New Phytologist, 161, 91-96.

Losos, J.B. (1996) Ecological and evolutionary determinants of the species-area relation in Caribbean anoline lizards. Philosophical Transactions of the Royal Society B: Biological Sciences, 351, 847-854.

Losos, J.B. \& Schluter, D. (2000) Analysis of an evolutionary species-area relationship. Nature, 408, 847-850.

MacArthur, R.H. \& Wilson, E.O. (1963) An equilibrium theory of insular zoogeography. Evolution, 17, 373-387.

MacArthur, R.H. \& Wilson, E.O. (1967) The theory of island biogeography. Princeton University Press, Princeton.

Machado, A. (1988) Two new cavernicolous species of the genus Trechus Clairv. from the Azores (Coleoptera, Carabidae). Bocagiana, 119, 1-8.

Machado, A. (1990) Nuevos Carábidos microftalmos de la isla de La Palma, Islas Canarias (Coleoptera, Carabidae). Nouvelle Revue d'Entomologie (N.S.), 6, 369-372.

McCullagh, P. \& Nelder, J.A. (1989) Generalized linear models, 2nd edn. Chapman \& Hall, London.

Nathan, R. (2005) Long-distance dispersal research: building a network of yellow brick roads. Diversity and Distributions, 11, 125-130.

Nunes, J.C.C. (1999) A actividade vulcânica na ilha do Pico do Plistocénico Superior ao Holocénico: mecanismo eruptivo e hazard vulcânico. PhD Thesis, Universidade dos Açores, Ponta Delgada, Açores.

O’Brien, S.J. \& Mayr, E. (1991) Bureaucratic mischief: recognizing endangered species and subspecies. Science, 251, 1187-1188.

Peck, S.B., Wigfull, P. \& Nishida, G. (1999) Physical correlates of insular species diversity: the insects of the Hawaiian Islands. Annals of the Entomological Society of America, 92, 529-536.

Pereira, F., Borges, P.A.V., Costa, M.P., Constância, J.P., Nunes, J.C., Barcelos, P., Braga, T., Gabriel, R. \& Amorim, I.R. (in press) Catalogue of the Azorean caves (volcanic pits, lavatubes and sea erosion caves). Direcção Regional do Ambiente, Horta.

Pereira, H.M., Proença, V.M. \& Vicente, L. (2007) Does species diversity really drive speciation? Ecography, 30, 328-330.

Phillimore, A.B., Orme, C.D.L., Davies, R.G., Hadfield, J.D., Reed, W.J., Gaston, K.J., Freckleton, R.P. \& Owens, I.P.F. (2007) Biogeographical basis of recent phenotypic diver- gence among birds: a global study of subspecies richness. Evolution, 61, 942-957.

Ribeiro, S.P., Borges, P.A.V., Gaspar, C., Melo, C., Serrano, A.R.M., Amaral, J., Aguiar, C., André, G. \& Quartau, J.A. (2005) Canopy insect herbivores in the Azorean Laurisilva forests: key host plant species in a highly generalist insect community. Ecography, 28, 315-330.

Rosenzweig, M.L. (1995) Species diversity in space and time. Cambridge University Press, Cambridge.

Rosenzweig, M.L. (2001) Loss of speciation rate will impoverish future diversity. Proceedings of the National Academy of Sciences USA, 98, 5404-5410.

Rosenzweig, M.L. (2003) Reconciliation ecology and the future of species diversity. Oryx, 37, 194-205.

Schluter, D. (2000) The ecology of adaptive radiation. Oxford University Press, Oxford.

Serralheiro, A. \& Madeira, J. (1993) Stratigraphy and geochronology of Santa Maria Island (Azores). Açoreana, 7, 575-592.

StatSoft Inc. (2003) STATISTICA (data analysis software system), version 6.1. StatSoft, Inc., Tulsa.

Stephens, P.R. \& Wiens, J.J. (2003) Explaining species richness from continents to communities: the time-for-speciation effect in emydid turtles. The American Naturalist, 161, 112128.

Stuessy, T.F. (2007) Evolution of specific and genetic diversity during ontogeny of island floras: the importance of understanding process for interpreting island biogeographic patterns. Biogeography in a changing world, Systematics Association Special Volume, no. 70 (ed. by M.C. Ebach and R.S. Tangney), pp. 117-133. CRC Press, Boca Raton.

Stuessy, T.F., Jakubowsky, G., Gomez, R.S., Pfosser, M., Schluter, P.M., Fer, T., Sun, B.-Y. \& Kato, H. (2006) Anagenetic evolution in island plants. Journal of Biogeography, 33, 12591265.

Thornton, I. (2007) Island colonization. The origin and development of island communities. Cambridge University Press, Cambridge.

Triantis, K.A., Nogués-Bravo, D., Hortal, J., Borges, P.A.V., Adsersen, H., Fernández-Palacios, J.M., Araújo, M.B. \& Whittaker, R.J. (2008) Measurements of area and the (island) species-area relationship: new directions for an old pattern. Oikos, doi: 10.1111/j.2008.0030-1299.16808.x.

Whittaker, R.J. (2006) Island species-energy theory. Journal of Biogeography, 33, 11-12.

Whittaker, R.J. \& Fernández-Palacios, J.M. (2007) Island biogeography: ecology, evolution, and conservation, 2nd edn. Oxford University Press, Oxford.

Whittaker, R.J., Ladle, R.J., Araújo, M.B., Fernández-Palacios, J.M., Domingo Delgado, J. \& Arévalo, J.R. (2007) The island immaturity - speciation pulse model of island evolution: an alternative to the 'diversity begets diversity' model. Ecography, 30, 321-327.

Whittaker, R.J., Triantis, K.A. \& Ladle, R.J. (2008) A general dynamic theory of oceanic island biogeography. Journal of Biogeography, 35, 977-994. 
Williamson, M. (1988) Relationship of species number to area, distance and other variables. Analytical biogeography: an integrated approach to the study of animal and plant distributions (ed. by A.A. Myers and P.S. Giller), pp. 91-115. Chapman \& Hall, London.

Wilson, E.O. (1969) The species equilibrium. Brookhaven Symposium of Biology, 22, 38-47.

Wilson, E.O. \& Taylor, R.W. (1967) An estimate of the potential evolutionary increase in species density in the Polynesian ant fauna. Evolution, 21, 1-10.

\section{SUPPORTING INFORMATION}

Additional Supporting Information may be found in the online version of this article:

Appendix S1 List of the arthropod single-island endemics of the seven Azorean islands studied, and their distribution.

Please note: Wiley-Blackwell is not responsible for the content or functionality of any supporting materials supplied by the authors. Any queries (other than missing material) should be directed to the corresponding author for the article.
BIOSKETCHES

Paulo A. V. Borges is a professor in the Department of Agriculture of the University of the Azores and leads the Azorean Biodiversity Group of CITA-A. His ongoing research focuses on the study of the biodiversity of Azorean arthropods, with emphasis on taxonomy, ecology (macroecology), biospeleology and biogeography. $\mathrm{He}$ is also interested in the development of species-area models that could describe patterns of species richness and potential extinction on islands.

Joaquín Hortal is currently a research associate at the NERC Centre for Population Biology of Imperial College at Silwood Park. He studies the factors influencing current and past biodiversity patterns, especially those affecting the assemblage and structure of communities through time, as well as evolutionary processes in a biogeographical extent. He is also interested in island biogeography, biodiversity estimators, conservation biogeography, predictive modelling of species distributions and the ecology, evolution and biogeography of dung beetles.

Editor: Lawrence Heaney 